\title{
A novel mutation of Dent's disease in an 11-year-old male with nephrolithiasis and nephrocalcinosis
}

\author{
Ozlem Sancakli, M.D. ${ }^{a}$, Bahar Kulu, M.D. ${ }^{a}$ and Onur Sakallioglu, M.D. ${ }^{a}$
}

\begin{abstract}
Dent's disease is a rare $\mathrm{X}$-linked recessive tubulopathy characterized by low molecular weight (LMW) proteinuria, hypercalciuria, nephrolcalcinosis or nephrolithiasis, proximal tubular dysfunction and renal failure in adulthood. Females are carriers and usually mildly affected. Progression to endstage renal failure are at the 3rd-5th decades of life in 30-80\% of affected males. In the absence of therapy targeting for the molecular defect, the current care of patients with Dent's disease is supportive, focusing on the prevention of nephrolithiasis and nephrocalcinosis. We present an 11-year-old child with nephrocalcinosis and nephrolithiasis caused by a new mutation at CLCN5 gene.
\end{abstract}

Key words: Nephrolithiasis, proximal renal tubular dysfunction, nephrocalcinosis, Dent's disease, CLCN5.

http: / / dx.doi.org/10.5546/ aap.2018.eng.e442

To cite: Sancakli O, Kulu B, Sakallioglu O. A novel mutation of Dent's disease in an 11-year-old male with nephrolithiasis and nephrocalcinosis. Arch Argent Pediatr 2018;116(3):e442-e444.

\section{INTRODUCTION}

Nephrocalcinosis is characterized by the deposition of calcium in the kidney parenchyma and tubules. It is associated with conditions that cause hypercalcemia, hyperphosphatemia, and the increased excretion of calcium, phosphate, and / or oxalate in the urine. ${ }^{1}$

Dent's disease is a rare cause of hypercalciuria without hypercalcemia. It is characterized by low molecular-weight (LMW) proteinuria, hypercalciuria, nephrocalcinosis, nephrolithiasis, proximal tubular dysfunction and renal failure in

a. Department of Pediatrics, Başkent University Zübeyde Hanım Research Hospital, Izmir, Turkey.

E-mail address:

Ozlem Sancakli, M.D.:sancakliozlem@yahoo.com

Funding: None.

Conflict of interest: None.

Received: 8-9-2017

Accepted: 11-15-2017 adulthood., ${ }^{2,3}$ The physiopathology of tubulopathy is due to the inactivation of the $C L C N-5$ exchanger (chloride voltage-gated channel 5) at proximal tubules. Patients with a mutation at CLCN5 gene encoding CLCN-5 channel are classified as having Dent's disease type 1, while patients with a mutation at OCRL gene encoding inositol polyphosphate-5-phosphatase are classified as Dent's disease type 2. ${ }^{4}$ Both forms of Dent's disease are X-linked, and males, who are hemizygous, are affected more severely. Females, who are usually only mildly affected, are carriers. ${ }^{5}$

We present an 11-year-old child with nephrocalcinosis and nephrolithiasis who detected a new mutation in CLCN5 gene.

\section{CASE REPORT}

An 11-year old boy was referred for nephrolithiasis and nephrocalcinosis detected at investigation of acute abdominal pain in emergency department. He denied any renal disease, trauma, diarrhea or constipation at past medical history. The parents is nonconsanguineous and grandmother had renal failure of unknown origine at medical family history. There was no pathological finding on the physical examination, including growth parameters and blood pressure according to age group. Laboratory findings were normal except hypercalciuria $(9 \mathrm{mg} / \mathrm{kg} / \mathrm{d}), 88 \%$ tubular phosphore reabsorbtion rate (TPR), low molecular weight proteinuria (Beta-2 microglobulin $5080 \mathrm{mcg} / \mathrm{L}, \mathrm{n}<250 \mathrm{mcg} / \mathrm{L}$ ) in 24 hour urine, bilateral $4 \mathrm{~mm}$ non obstructive nephrolithiasis and nephrocalcinosis at ultrasonography. Urinary oxalate, citrate, uric acid, serum bicarbonate, phosphor, vitamin-D and parathormone values were also normal. Based on the clinical criteria of Dent's disease, genetic analysis was considered for Dent's disease in advance. The mutation in the CLCN-5 gene (c.2010_2010 del G or p.Asp671fs) was detected in frame shift and identified as a stop codon (Figure 1).

In the follow-up of the case, our patient has been treated with potassium citrate and thiazide for three years. There was no pathological finding to progression of end-stage renal failure in 
laboratory tests. Genetic counseling was given to the patient's family for Dent's disease.

\section{DISCUSSION}

According to the laboratory results, three groups can be formed in patients with nephrocalcinosis to make a differential diagnosis; hypercalciuria with hypercalcemia, hypercalciuria without hypercalcemia and hyperphosphaturia. Our patient fulfilled the criteria of the group of hypercalciuria without hypercalcemi rather than the groups of hypercalciuria with hypercalcemia and hyperphosphaturia among the three groups of nephrocalcinosis. Distal renal tubular acidosis, medullar sponge kidney, neonatal nephrocalcinosis, loop diuretics, inherited tubulopathies (Dent's disease etc.), chronic hypokalemia and beta thalassemia are the underlying diseases in association with the group of hypercalciuria without hypercalcemia at nephrocalcinosis. ${ }^{1}$ The clinical diagnosis of Dent's disease is based on the presence of all of criteria: Low Molecular Weight (LMW) proteinuria (elevation of urinary excretion of beta2microglobulin, Clara cell protein and/or RBP by at least 5-fold above the upper limit of normalthe pathognomonic finding of Dent's disease), hypercalciuria ( $>4 \mathrm{mg} / \mathrm{kg}$ in a 24 hour collection or $>0.25 \mathrm{mg} \mathrm{Ca} 2+/ \mathrm{mg}$ creatinine on a spot sample), and at least one of the following criteria: nephrocalcinosis, nephrolithiasis, hematuria, hypophosphatemia and chronic renal disease. ${ }^{6,7}$ Nephrocalcinosis, nephrolithiasis, normal blood $\mathrm{pH}, \mathrm{LMW}$ proteinuria, hypercalciuria and lower TPR without hypercalcemia pointed out Dent's disease in our patient. Genetical analysis also confirmed the diagnosis with the mutation in CLCN-5 gene.

Although CLCN5 gene mutations are shown in about $60 \%$ of patients with X-linked nephrolithiasis, OCRL gene mutations are in 15\%. The both of gene are normal at remaining 25\% patients. ${ }^{2,3}$ The exact prevalence of Dent's disease is undefined; to date, $>250$ families have been described. ${ }^{5}$ Hypercalciuria and nephrocalcinosis are prevalent at a rate of $95 \%$ and $75 \%$ in affected males, respectively. Progression to end-stage renal failure are at the $3^{\text {rd }}-5^{\text {th }}$ decades of life in $30-80 \%$ of affected males. ${ }^{8,9}$ Due to be the initial report and at early-stage, we could not define genotype-phenotype correlations for novel mutation. Comparatively silent presentation of our patient may be specific aspect for this mutation at early stage. The other potential (including end-stage renal failure) or unreported aspects of disease may be met later in our patient with this novel mutation. But it is definite that Dent's disease may be seen in patients with this mutation at CLCN5 gene.

In the absence of therapy targeting for the molecular defect, the current care of patients with Dent's disease is supportive, focusing

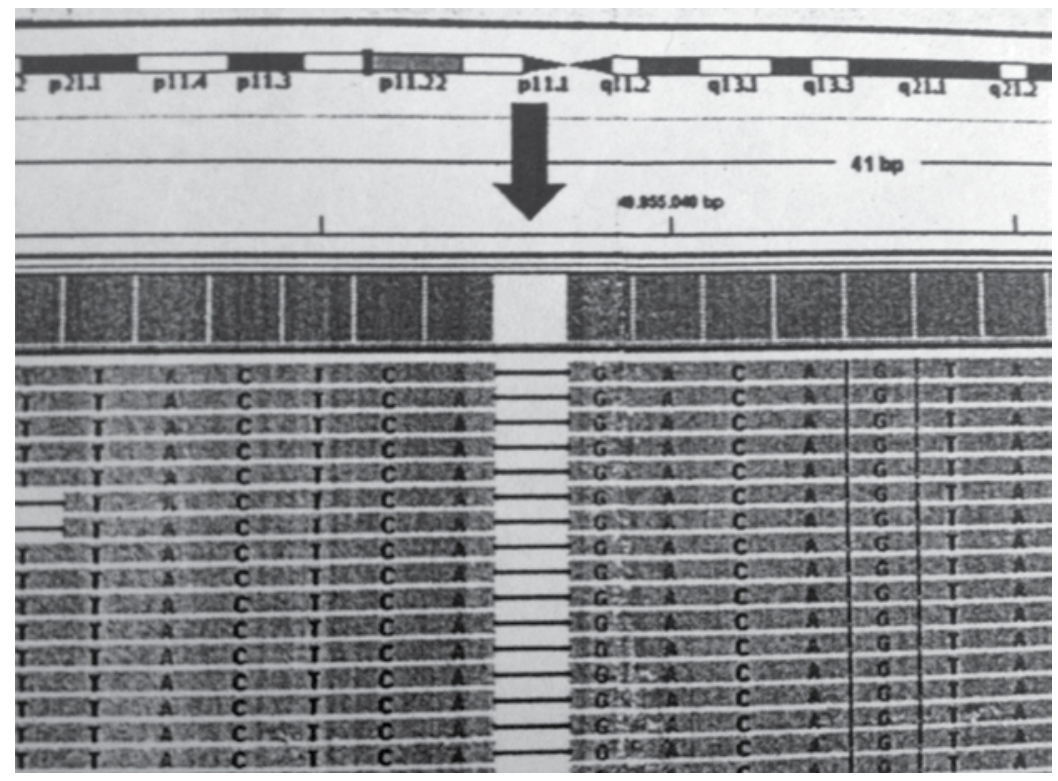


on the prevention of nephrolithiasis and nephrocalcinosis. Thiazide diuretics can be used to treat hypercalciuria. ${ }^{10,11}$

Up to rarely seen, we think the new mutation in the CLCN-5 gene will enlight and contribute the potential findings and studies relevant to Dent's disease in future. Dent's disease should be kept in mind in nephrocalcinosis with hypercalciuria, LMW proteinuria and normal blood $\mathrm{pH}$ at male patients.

\section{REFERENCES}

1. Wrong O. Nephrocalcinosis. In: Davison AM, Cameron JS, Grünfeld J, et al. eds. Oxford Textbook of Clinical Nephrology. 3rd ed. Oxford: Oxford University Press; 2005.P.1257-80.

2. Ludwig M, Utsch B, Monnens LA. Recent advances in understanding the clinical and genetic heterogeneity of Dent's disease. Nephrol Dial Transplant 2006;21:2708-17.

3. Thakker RV. Pathogenesis of Dent's disease and related syndromes of X-linked nephrolithiasis. Kidney Int 2000;57(3):787-93.
4. Böckenhauer D, Bökenkamp A, Nuutinen M, et al. Novel OCRL mutations in patients with Dent-2 disease. J Pediatr Genet 2012;1(1):15-23.

5. Ludwig M, Utsch B, Balluch B, et al. Hypercalciuria in patients with CLCN5 mutations. Pediatr Nephrol 2006;21(9):1241-50.

6. Hoopes RR Jr, Raja KM, Koich A, et al. Evidence for genetic heterogeneity in Dent's disease. Kidney Int 2004;65(5):1615-20.

7. Edvardsson VO, Goldfarb DS, Lieske JC, et al. Hereditary causes of kidney stones and chronic kidney disease. Pediatr Nephrol 2013;28(10):1923-42.

8. Devuyst O, Thakker RV. Dent's disease. Orphanet J Rare Dis 2010;5:28.

9. Scheinman SJ. X-linked hypercalciuric nephrolithiasis: clinical syndromes and chloride channel mutations. Kidney Int 1998;53:3-17.

10. Raja KA, Schurman S, D'mello RG, et al. Responsiveness of hypercalciuria to thiazide in Dent's disease. J Am Soc Nephrol 2002;13(12):2938-44.

11. Blanchard A, Vargas-Poussou R, Peyrard S, et al. Effect of hydrochlorothiazide on urinary calcium excretion in Dent disease: an uncontrolled trial. Am J Kidney Dis 2008;52(6):1084-95. 